УДК 330.7:334.012.62(47+57)

\title{
СОЦИОЛОГИЧЕСКИЙ АНАЛИЗ СОЦИАЛЬНОЙ БЕЗОПАСНОСТИ СОВРЕМЕННОГО КРУПНОГО РОССИЙСКОГО ПРЕДПРИЯТИЯ
}

\author{
Кареева Анна Петровна, \\ karenina3010@rambler.ru \\ Северный (Арктический) Федеральный университет им. М.В. Ломоносова, \\ Россия, 163002, г. Архангельск, набережная Северной Двины, 17
}

Кареева Анна Петровна, соискатель, Северный (Арктический) Федеральный университет им. М.В. Ломоносова.

\begin{abstract}
Актуальность исследования определена наличием в современном обществе значительного количества рисков и желанием людей, живущих в нем, обезопасить себя от их негативного воздействия. Социальная жизнь в таком рискогенном обществе характеризуется неопределенностью. Институциональные среды риска охватывают как отдельные социальные группы, так и все человечество. Безопасность при этом выступает сдерживающим элементом, который не дает разрушить сложившуюся социальную структуру данного общества и смягчает возникающие в нем социальные риски. Цель работы: изучить социальную безопасность современного крупного российского предприятия, создать теоретическую модель и провести её практический анализ. Методы исследования: теоретико-методологической основной исследования стали труды ученых, сформировавших основные подходы к пониманию концепции «общества риска», теории институциональных матриц, социальной безопасности, социологии труда и универсумной социологической парадигмы. В рамках исследования проведен социально-исторический анализ открытых документальных источников, контент-анализ печатных средств массовой информации, анкетный опрос и сравнительный анализ представлений руководства и работников отдельных промышленных предприятий атомной отрасли. Результаты: выявлены основные характеристики социального риска, дано его определение, описана социальная сфера современного рискогенного общества. Безопасность при этом рассмотрена как базовый социальный институт такого общества. В нем выделены «внутренняя структура» института и его институциональные формы. Социальная безопасность определена одной из таких форм. Анализ социальной безопасности крупного российского предприятия проведен на различных уровнях социума (макро-, мезо- и микроуровень), создана теоретическая модель. Практический анализ теоретической модели социальной безопасности проведен на отдельных промышленных предприятиях атомной отрасли. Такими предприятиями стали ГХК (г. Железногорск, Красноярский край), СХК (2. Северск, Томская область), ПО «Маяк» (2. Озерск, Челябинская область) и Атомфлот (2. Мурманск, Мурманская область).
\end{abstract}

Ключевые слова: Безопасность, социальная безопасность, институт, рискогенное общество, социальный риск, промышленное предприятие.

В современном обществе риски являются нашими постоянными спутниками, избавиться от них становится все труднее. Мировые кризисы все интенсивнее сотрясают планету, неся с собой масштабные последствия для социальной сферы общества. Среди них - ослабление рабочего класса, увеличение неравенства доходов, рост безработицы и инфляции, падение потребительского спроса, усиление социальных страхов и т. д. В процессе ускоряющегося динамизма происходят изъятие социальных отношений из локального контекста и включение их в глобальный посредством пространственно-временной дистанцированности, «открепления» социальных институтов от локальных контекстов и 
их реструктурирование на сколь угодно больших отрезках пространства и времени. Социальная жизнь при этом характеризуется неопределённостью, а понятие риска становится центральным. Ему подвержен каждый, даже бездействие становится риском. В обществе образуются обширные институциональные среды риска, которые охватывают значительные социальные группы, а в отдельных случаях и все человечество. Таким образом, желание обезопасить себя становится важнейшей ценностью людей, живущих в таком обществе. Сделать это они могут с помощью социальной безопасности. Согласно концепции «общества риска» социальная безопасность в современном обществе направлена на минимизацию возникающих в нём социальных рисков. Полностью устранить их, к сожалению, невозможно: она способна только смягчить их проявления. Цель статьи изучить социальную безопасность современного крупного российского предприятия, создать теоретическую модель и провести её практический анализ.

\section{Безопасность как социальный институт}

Безопасность через социологию риска изучали М. Дуглас [1], У. Бек [2], Н. Луман [3], Э. Гидденс [4], А. Альгин [5], М. Гринберг [6], В. Зубков [7], С. Никитин [8], К. Феофанов [9] и др. Они рассматривали вопросы, связанные с управлением рисками, помимо «материальных» оценок потерь учитывали экономические, общекультурные издержки, которые влекли за собой риски, нашли связь оценок риска с ценностями и нормами социального характера. В рамках данного исследования важное методологическое значение приобрели генерализирующие концепции, позволяющие рассматривать современное общество как «общество риска», созданные У. Беком, Н. Луманом и Э. Гидденсом. Обобщив их труды, удалось описать социальную сферу современного общества, дать определение социальному риску и выявить его основные характеристики.

Социальная среда современного общества понимается как среда, в которой риск является центральным элементом. Люди, сталкиваясь с институциональными средами риска, принимают различные решения, находясь в ситуации неопределённости. «Ценностный политеизм» становится центральным явлением современной действительности и приводит к отсутствию абсолютного авторитета (эксперта). Человек в повседневной жизни вынужден сам интерпретировать происходящее и определять, какому мнению для устранения возникающего риска он доверяет больше. Социальные отношения при этом формируются на основе «активного доверия», которое возникает между ним и системой или между двумя индивидуумами. Однако, находясь в настоящем, люди вынуждены принимать решения о рисках, которые ещё не произошли, но возможно произойдут в будущем. Быть полностью уверенными в правильности принимаемых решений они не могут. Поэтому относительно своего будущего у абсолютно каждого человека возникает чувство страха. Если принятое решение позволяет предотвратить и/или компенсировать возникающий риск, то данное решение людьми признается правильным, а риск - приемлемым. Если нет, то под угрозу ставится «пакт безопасности», заключенный между субъектом и объектом риска. Данный договор лежит в основе процессов модернизации в современном обществе. При его разрушении в обществе возникает протест против дальнейших изменений. Поэтому социальный риск понимается нами как вероятность возникновения какого-либо отрицательного события, приводящего к трансформации приемлемого риска в угрозу для дальнейшего существования индивида, социальной группы или общества. Основными его характеристиками являются глобальность, систематичность проявления, всеобщность, неустранимость, современные причины возникновения, неопределённость при принятии решения, дальнодействие, перенасыщенность знаний о данной проблеме. Отрицательное событие возникает только в том случае, если между 
субъектом и объектом риска отсутствует эффективное социальное взаимодействие. Безопасность при этом призвана минимизировать это отрицательное событие.

Анализ безопасности с позиции институционального подхода позволил отнести её к базовым институтам современного общества риска. Изучением социальных явлений через институциональный подход занимаются отечественные и зарубежные ученые (Т. Веблен [10], Дж. Коммонс [11], У. Митчелл [12], У. Гамильтон [13], О. Иншаков [14], Ю. Осипов [15], В. Радаев [16], Т. Заславская [17], 3. Калугина [18] и др.). В России институциональный подход к исследованию социальных явлений представлен двумя школами - «московской» и «новосибирской». Опираясь на теорию структурации Э. Гидденса [19] и теорию институциональных матриц С. Кирдиной [20], под безопасностью в данном исследовании нами понимается социальный институт, направленный на минимизацию, управление и создание способов, препятствующих трансформации приемлемого риска в угрозу для дальнейшего существования индивида, социальной группы или общества.

Современное общество рискогенно и динамично. Безопасность в нем выступает тем сдерживающим элементом, который не даёт разрушить сложившуюся структуру. Она вносит определённый порядок в ситуацию неопределённости, через превентивные меры позволяет индивиду, группе или обществу достичь относительной безопасности в ситуации социального риска. Благодаря ей удаётся сохранить риск в категории приемлемого, не позволяя ему трансформироваться в угрозу для дальнейшего существования общества на различных уровнях социума. Институт безопасности проявляется в глобальном масштабе, пронизывает все сферы общественной жизни (от макро- до микроуровня), формирует современную идеологию и социальные отношения (рис. 1).

\begin{tabular}{|c|c|c|c|}
\hline \multicolumn{2}{|c|}{$\begin{array}{l}\text { Информационная безопасность } \\
\text { Information Security }\end{array}$} & $\begin{array}{r}\text { Национальная безопа } \\
\text { National Securit }\end{array}$ & $\begin{array}{c}\text { Социальная безопасность } \\
\text { Social Security }\end{array}$ \\
\hline & \multirow{3}{*}{\multicolumn{2}{|c|}{$\begin{array}{c}\text { глобальность, систематичность проявления, проникновение } \\
\text { во все уровни социума, устойчивые социальные отношения } \\
\text { («стремление достичь относительной безопасности в ситуа- } \\
\text { ции социального риска») наличие чувства страха, превен- } \\
\text { тивный характер используемых мер } \\
\text { globality, systematic manifestation, penetration into all levels of } \\
\text { society, stable social relations («the desire to achieve relative } \\
\text { security in a situation of social risk»), the presence of a sense of } \\
\text { fear, the preventive nature of the measures used }\end{array}$}} & \multirow{3}{*}{$\begin{array}{c}\text { Продовольственная } \\
\text { безопасность } \\
\text { Food Security }\end{array}$} \\
\hline \multirow[t]{2}{*}{$\begin{array}{c}\text { Экономическая без- } \\
\text { опасность } \\
\text { Economic Security }\end{array}$} & & & \\
\hline & & & \\
\hline $\begin{array}{l}\text { Личная безопасность } \\
\text { Personal Security }\end{array}$ & & $\begin{array}{l}\text { Ядерная безопасность } \\
\text { Nuclear Security }\end{array}$ & $\begin{array}{c}\text { безопасность } \\
\text { Environmental Security }\end{array}$ \\
\hline
\end{tabular}

Pис. 1. Институт безопасности в современном обществе риска, состоящий из «внутренней» (постоянной) структуры и институциональных форм, количество которых напрямую зависит от культурно-исторических условий

Fig. 1. Institution of security in a modern risk society, consisting of an «internal» (permanent) structure and institutional forms, the number of which directly depends on cultural and historical conditions

Опираясь на теорию институциональных матриц С. Кирдиной, авторы пришли к выводу, что институт безопасности имеет следующие постоянные особенности: «Глобальность и систематичность проявления, проникновение во все уровни социума (от 
макро- до микроуровня), сформированность устойчивых социальных отношений, которые можно охарактеризовать как «стремление достичь относительной безопасности в ситуации социального риска», наличие чувства страха, превентивный характер используемых мер для устранения рисков» [21]. Значительное количество институциональных сред риска приводит к формированию в современном обществе значительного количества видов безопасности. Именно они являются институциональными формами института безопасности. Формирование института безопасности и его институциональных форм исторически обусловлено.

\section{Социальная безопасность современного российского предприятия}

Несмотря на то, что толчком к изучению социальной безопасности стал процесс развития капитализма, в ходе которого произошло разделение экономической и социальной сфер, до сегодняшнего дня нет единого подхода к её определению. Социальная безопасность рассматривается через призму национальной безопасности; глобализацию и теорию устойчивого развития; влияние изменяющейся среды на личность и сознание человека; защиту населения от целого ряда угроз; отдельные социальные риски. В данном исследовании социальная безопасность выступает институциональной формой института безопасности современного рискогенного общества, т. е. по сути является институTом.

Используя теорию институциональных матриц, предложенную С. Кирдиной, удалось изучить социальную безопасность современного российского предприятия на различных уровнях социума.

Макроуровень. На макроуровне субъектом социальной безопасности выступает отрасль. Система управления, применяемая на уровне отрасли, как правило, повторяет российскую управленческую вертикаль (центр-регионы-муниципалитеты). Это выглядит так: отрасль (атомная, космическая, энергетическая) - группа или дивизион (несколько предприятий, схожих по выпуску продукции, виду деятельности и т. д.) - предприятие.

Руководство отрасли, понимая, что современное российское общество рискогенно, вынуждено постоянно реагировать на возникающие в нём социальные риски через принятие тех или иных решений, направленных на их минимизацию. При этом используемые меры носят превентивный характер. Ведь принимая решения, руководство ориентируется не на риски, которые уже произошли, а на риски, возникновение которых возможно в будущем. Данные решения определяют отраслевую стратегию и тактику в области социальной безопасности. Они едины для всех предприятий отрасли и свое отражение находят в социальной политике. Иными словами, социальная политика выступает средством, которое применяет руководство отрасли для минимизации социальных рисков, возникающих в социальной сфере, входящих в её состав предприятий. Принципами функционирования социальной безопасности в рамках отрасли являются единство на всех предприятиях, законность, ответственность, равенство возможностей, справедливость при распределении собственности и доходов, приоритетность, перспективность. Итогом социальной безопасности выступает её результативность. При положительной результативности принятые руководством отрасли решения позволяют сохранить риск на уровне приемлемого как для субъекта, так и для объекта риска. При отрицательной результативности приемлемый риск трансформируется в угрозу для дальнейшего существования отдельного предприятия, группы предприятий или всей отрасли. 
Для подробного анализа социальной политики, реализуемой в рамках отрасли для минимизации рискогенных ситуаций, использованы социальные резервы труда, предложенные Ж. Тощенко [22]. Благодаря им выделены направления социальной политики, а также социальные риски, негативные последствия которых руководство старается минимизировать в социальной среде отраслевых предприятий при их возникновении (рис. 2).

Направления социальной политики Directions of social policy

Экономическое благосостояние работника Economic well-being of the employee

Производственная безопасность работника Industrial security of the employee

Профессиональный рост работника

Professional growth of the employee

Творческая активность работника

Creative activity of the employee

Производственные условия труда работника

Working conditions of the employee

Ощущение работником социальной стабильности

Employee's sense of social stability

Получение работником обратной связи/Getting employee feedback
Возможные социальные риски Possible social risks

Снижение экономического благосостояния работника

Reducing the economic well-being of the employee

Снижение производственной безопасности работника

Reducing the worker's occupational security

Падение научно-технического и технологи-

ческого потенциала работника

Decline in the scientific, technical and techno-

logical potential of the employee

Снижение здоровья работника

Reduced employee health

Снижение экологической безопасности работника

Reducing the environmental security of the employee

Падение социальной стабильности предприятия в глазах работника

Decline in the social stability of the enterprise in the eyes of the employee

Падение значимости обратной связи в глазах работника

Decline in the importance of feedback in the eyes of the employee

Pис. 2. Направления отраслевой социальной политики, призванные минимизировать возникающие в социальной среде предприятий риски

Fig. 2. Directions of sectoral social policy designed to minimize the risks arising in the social environment of enterprises

Согласно теории институциональных матриц, сформировавшись на макроуровне, отраслевая социальная безопасность спускается на мезо- и микроуровни.

Мезоуровень. Представлен отраслевым дивизионом. В его состав входят предприятия, схожие по технологическим параметрам (продукция, разработки и т. д.). В отличие от отрасли, которая является субъектом социальной безопасности, дивизион выступает её объектом. В его социальной среде реализуется стратегия, тактика, принципы, методы, социальная политика и её направления, провозглашенные на отраслевом уровне. Дивизион обладает возможностью выбирать меры, которые помогут минимизировать негативные последствия возникающих в социальной среде предприятий рискогенных ситуаций. Если мер не хватает, то их расширение происходит только на отраслевом уровне.

Микроуровень. Представлен современным крупным российским предприятием. Российское предприятие, как и дивизион, выступает по отношению к отрасли объектом 
социальной безопасности. Для минимизации негативных последствий возникающих социальных рисков пользуется мерами, закрепленными в отраслевой социальной политики. Потребителями социальной безопасности предприятия выступают руководство и работники.

Работник является центральной, определяющей фигурой производственного процесса. Несмотря на то, что он объединяет вокруг себя все факторы и условия производства и от его деятельности зависит производительность труда и эффективность производства, средства производства, которые работник использует, ему не принадлежат. Его главной ценностью является труд, который он продает, вступая с руководством в трудовые отношения. Значительный вклад в изучение трудовых отношений внесли отечественные и зарубежные социологи. Среди них Ф. Тейлор [23], Э. Мэйо, [24], А. Гастев [25], А. Здравомыслов [26], О. Шкаратан [27], С. Фролов [28] и др. Благодаря их исследованиям в трудовые отношения были включены социально-экономические, социально-личностные, творческие и гражданские условия труда работника. Поэтому в ситуации, когда каждое современное российское предприятие испытывает влияние рискогенной среды, наёмные работники боятся потерять не сам труд, а вознаграждения, которые дают сложившиеся на предприятии условия труда. Другими словами, работники боятся потерять вознаграждения за трудовые отношения. Для их защиты они обращаются к руководству. Между ними заключается «пакт безопасности», в котором, с одной стороны, учитывается факт появления рисков, а с другой - работники вовлекаются в процесс их предотвращения и компенсации. В основе пакта лежит устойчивое социальное взаимодействие между работниками и руководством, которое можно охарактеризовать как «стремление достичь относительной безопасности в ситуации социального риска». Оно всегда предметно, проявляется через коммуникацию и активное доверие и выражается в форме кооперации, конкуренции и конфликта. Чем больше работник доверяет руководству, тем эффективнее складывается между ними коммуникация, тем правильнее принимаемые руководством меры по минимизации негативных последствий социальных рисков, тем выше социальная безопасность промышленного предприятия.

Отметим, что в рамках одной отрасли микроуровни предприятий могут существенно отличаться друг от друга. В этой ситуации социальное взаимодействие становится важным элементом выстраивания эффективной социальной безопасности на иерархических уровнях «предприятие-дивизион-отрасль». Ведь оно позволяет корректировать отраслевую социальную политику в зависимости от социальной ситуации конкретного предприятия.

Руководство предприятия всегда выступает субъектом социальной безопасности по отношению к своим работникам. Именно оно, согласно управленческой вертикали, отвечает за выбор тех или иных мер, направленных на минимизацию негативных последствий, возникающих в социальной среде предприятия рискогенных ситуаций. При этом перечень мер, которыми руководство может пользоваться, четко ограничен отраслевой социальной политикой. Работник одновременно является и субъектом, и объектом социальной безопасности. В качестве объекта он испытывает на себе те меры, которые принимаются руководством для минимизации негативных последствий возникающих рискогенных ситуаций. В качестве субъекта наёмный работник требует от руководства сохранить его трудовую жизнь относительно безопасной, т. е. не допустить снижения вознаграждения за трудовые отношения. Данное требование выполнимо только, если в социальной среде предприятия присутствуют исключительно приемлемые риски. В этом случае у работника снижается страх потери вознаграждения, а социальная безопасность признается результативной. Если нет, то её необходимо изменить, начиная с отраслевого 
уровня. Вектор результативности социальной безопасности определяет тип производственного социума, который преобладает в данный исторический период в социальной среде конкретного предприятия. Положительная результативность формирует социум, повышающий у наёмных работников уверенность в сохранении вознаграждения за трудовые отношения. Отрицательная результативность снижает такую уверенность, формируя социум, угрожающий наёмному работнику потерей вознаграждения за трудовые отношения.

Для анализа особенностей социальной безопасности с позиции работников предприятия нами использована постнеклассическая универсумная социологическая парадигма. Основой данной парадигмы выступает методологический принцип минимального универсума, сформулированный В. Немировским [29] и позволяющий описать структуру и динамику любой развивающейся системы. Кратко характеристики принципа можно выразить как два элемента, три уровня, пять состояний, семь слоев, двенадцать качеств.

В соответствии с методологическим принципом минимального универсума нерасчленённой протосистемой выступает наёмный работник. Двумя полярными элементами протосистемы «наёмный работник» являются социальная безопасность и социальный риск. В социальной среде предприятия они постоянно оказывают влияние на работника, формируя вокруг него производственный социум. Анализ трёх уровней методологического принципа минимального универсума выявил, что социальные риски оказывают негативное влияние на потребности работников предприятия (табл. 1). Их неудовлетворение приводит к усилению страха потери вознаграждения за трудовые отношения. И наоборот, чем выше вознаграждения работника за трудовые отношения, тем сильнее удовлетворяются его потребности.

Далее развитие социальной безопасности и социальных рисков современного предприятия проходит с образованием пяти стадий, семи слоев и двенадцати качеств.

Таким образом, использование различных подходов - институционального, представленного теорией институциональных матриц С. Кирдиной, социологии труда Ж. Тощенко, постнеклассической универсумной теории В. Немировского, социологии риска, представленной работами У. Бека, Н. Лумана и Э. Гидденса, - позволило системно проанализировать социальную безопасность крупного российского предприятия и создать её теоретическую модель (рис. 3).

\section{Социальная безопасность отдельных промышленных предприятий атомной отрасли. Сравнительный анализ позиций работников и руководства}

Полученная в ходе исследования теоретическая модель позволила изучить социальную безопасность отдельных промышленный предприятий атомной отрасли, таких как ГХК, СХК, ПО «Маяк» и Атомфлот. Предприятия управляются госкорпорацией «Росатом». Тема безопасности всегда была актуальна для них. Руководство на протяжении всего исторического периода существования предприятий требовало и требует от работников соблюдения множества технических и технологических регламентов безопасности. Работники в свою очередь предъявляют руководству требования сделать их производственную жизнь безопасной, защищённой от социальных рисков, возникновение которых возможно на предприятии. 


\section{Таблища 1. Негативное влияние социальных рисков на потребности работников} Table 1. Negative impact of social risks on the needs of employees

\begin{tabular}{|c|c|c|}
\hline $\begin{array}{l}\text { Уровни методологи- } \\
\text { ческого принципа } \\
\text { минимального } \\
\text { универсума } \\
\text { Levels of the minimum } \\
\text { universe methodologi- } \\
\text { cal principle }\end{array}$ & $\begin{array}{c}\text { Социальные риски } \\
\text { Social risks }\end{array}$ & $\begin{array}{l}\text { Потребности работников } \\
\text { Employee needs }\end{array}$ \\
\hline $\begin{array}{l}\text { Вещественно-энерге- } \\
\text { тический уровень } \\
\text { Material-energy level }\end{array}$ & $\begin{array}{l}\text { Снижение экономического благосо- } \\
\text { стояния работника. } \\
\text { Снижение производственной безопас- } \\
\text { ности работника. } \\
\text { Снижение здоровья работника. } \\
\text { Снижение экологической безопасно- } \\
\text { сти pаботника } \\
\text { Reducing the economic well-being of the } \\
\text { employee. } \\
\text { Reducing the worker's occupational se- } \\
\text { curity. } \\
\text { Reduced employee health } \\
\text { Reducing the environmental security of } \\
\text { the employee }\end{array}$ & $\begin{array}{l}\text { Повседневные потребности (пища, } \\
\text { одежда, жилье, защита от производ- } \\
\text { ственных и бытовых травм, сохранение } \\
\text { здоровья и т. д.) } \\
\text { Everyday needs (food, clothing, housing, } \\
\text { protection from industrial and household } \\
\text { injuries, health preservation, and so on) }\end{array}$ \\
\hline $\begin{array}{l}\text { Функционально-орга- } \\
\text { низационный уро- } \\
\text { вень } \\
\text { Functional- } \\
\text { organizational level }\end{array}$ & $\begin{array}{l}\text { Падение социальной стабильности } \\
\text { предприятия в глазах работника } \\
\text { Decline in the social stability of the enter- } \\
\text { prise in the eyes of the employee }\end{array}$ & $\begin{array}{l}\text { Социальные потребности (социальные } \\
\text { связи как внутри первичного коллек- } \\
\text { тива, так и в рамках предприятия, уве- } \\
\text { ренность в завтрашнем дне, удовлетво- } \\
\text { ренность своим положением на пред- } \\
\text { приятии) Social needs (social relations } \\
\text { both within the primary team and within } \\
\text { the enterprise, confidence in the future, } \\
\text { satisfaction with their position in the enter- } \\
\text { prise) }\end{array}$ \\
\hline $\begin{array}{l}\text { Информационный } \\
\text { уровень } \\
\text { Information level }\end{array}$ & $\begin{array}{l}\text { Падение научно-технического и тех- } \\
\text { нологического потенциала работника. } \\
\text { Падение значимости обратной связи в } \\
\text { глазах работника } \\
\text { Decline in the scientific, technical and } \\
\text { technological potential of the employee. } \\
\text { Decline in the importance of feedback in } \\
\text { the eyes of the employee }\end{array}$ & $\begin{array}{l}\text { Потребность в управлении производ- } \\
\text { ством, в понимании значимости и весо- } \\
\text { мости своих решений для развития } \\
\text { предприятия, в профессиональном ро- } \\
\text { сте, в творческой инициативе } \\
\text { Need for production management, for un- } \\
\text { derstanding the significance and weight of } \\
\text { their decisions for the development of the } \\
\text { enterprise, for professional growth, for cre- } \\
\text { ative initiative }\end{array}$ \\
\hline
\end{tabular}

Социально-исторический анализ открытых документальных источников, охватывающих историю комбинатов, начиная с 1948 года и по настоящее время, показал наличие следующей иерархической вертикали управления: «отрасль (Минстредмаш/Минатом/Росатом) - дивизион (ЗЖСЦ/ЯОК/АО «ТВЭЛ») - предприятие (ГХК/СХК/Атомфлот/ПО «Маяк»)». Дивизион для комбинатов стал актуальным только в современный период - период модернизации. До этого управление предприятиями осуществлялось напрямую из отрасли. Выделенные в ходе анализа исторические периоды, такие как «период становления», «период расцвета», «кризисный период» и «период модернизации», показали изменчивость социальной среды атомных предприятий. Анализ направлений социальной политики в различные исторические периоды развития предприятий позволил определить для каждого из них социальные риски, результативность 
социальной безопасности, тип производственного социума и социальное взаимодействие, сложившееся в рамках управленческой вертикали (руководство и работники). Это дало возможность определить социальную безопасность для всех исторических периодов развития предприятий. В табл. 2 представлены уровни социальной безопасности для каждого изучаемого атомного предприятия, выраженные с помощью уровней принципа минимального универсума.

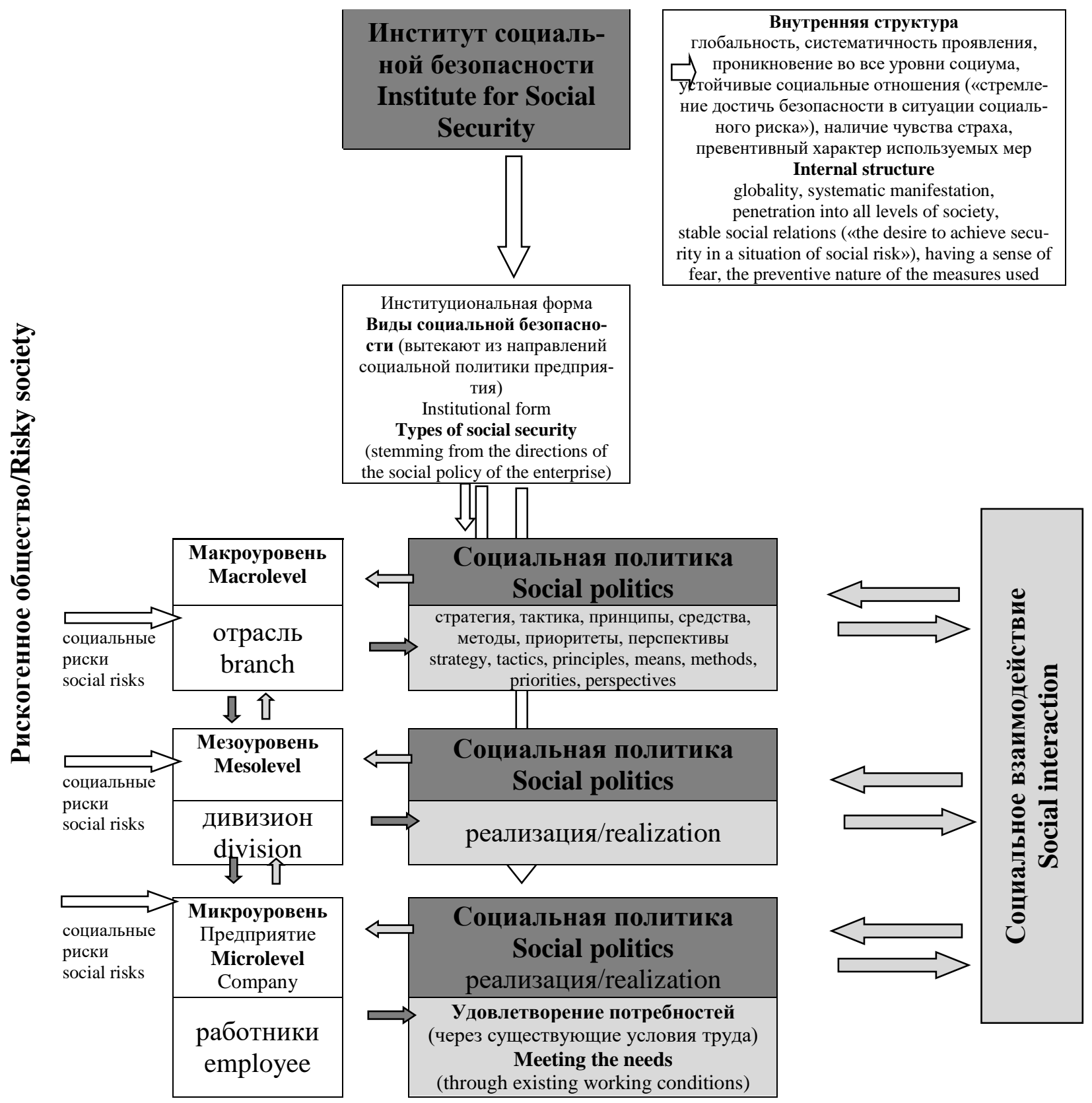

Pис. 3. Теоретическая модель института социальной безопасности современного крупного российского предприятия

Fig. 3. Theoretical model of the institution of social security of a modern large Russian enterprise 
Таблища 2. Социальная безопасность атомных предприятий в привязке к их историческим периодам развития (сравнительный анализ)

Table 2. Social security of nuclear enterprises in relation to their historical periods of development, comparative analysis

\begin{tabular}{|c|c|c|c|c|}
\hline \multirow[t]{2}{*}{$\begin{array}{c}\text { Исторические периоды } \\
\text { Historical periods }\end{array}$} & \multicolumn{4}{|c|}{$\begin{array}{l}\text { Атомные предприятия } \\
\text { Nuclear plants }\end{array}$} \\
\hline & $\Gamma \mathrm{XK} / \mathrm{MCC}$ & CXK/SHK & $\begin{array}{c}\text { ПО «Маяк» } \\
\text { PО Mayak }\end{array}$ & $\begin{array}{l}\text { Атомфлот } \\
\text { Atomflot }\end{array}$ \\
\hline $\begin{array}{l}\text { Период становления } \\
\text { Formation period }\end{array}$ & $\begin{array}{l}\mathrm{BЭУ} \rightarrow \mathrm{HУ} \\
\mathrm{MEL} \rightarrow \mathrm{IL}\end{array}$ & $\begin{array}{l}\mathrm{BЭУ} \rightarrow \text { ИУ } \\
\mathrm{MEL} \rightarrow \mathrm{IL}\end{array}$ & $\begin{array}{l}\mathrm{BЭY} \rightarrow \mathrm{UY} \\
\mathrm{MEL} \rightarrow \mathrm{IL}\end{array}$ & - \\
\hline $\begin{array}{l}\text { Период расцвета } \\
\text { Heyday }\end{array}$ & ИУ/IL & ИУ/IL & ИУ/IL & - \\
\hline $\begin{array}{l}\text { Кризисный период } \\
\text { Crisis period }\end{array}$ & $\begin{array}{l}\text { ИУ } \rightarrow \text { ВЭУ } \\
\mathrm{IL} \rightarrow \mathrm{MEL}\end{array}$ & $\begin{array}{l}\text { ИУ } \rightarrow \text { ВЭУ } \\
\mathrm{IL} \rightarrow \mathrm{MEL}\end{array}$ & $\begin{array}{l}\text { ИУ } \rightarrow \text { ВЭУ } \\
\mathrm{IL} \rightarrow \mathrm{MEL}\end{array}$ & - \\
\hline $\begin{array}{l}\text { Период модернизации } \\
\text { Modernization period }\end{array}$ & $\begin{array}{l}\text { ВЭУ } \rightarrow \text { BЭУ } \\
\mathrm{MEL} \rightarrow \text { MEL }\end{array}$ & $\begin{array}{l}\mathrm{BЭY} \rightarrow \text { ФOУ } \\
\mathrm{MEL} \rightarrow \text { FOL }\end{array}$ & $\begin{array}{l}\mathrm{BЭУ} \rightarrow \mathrm{UY} \\
\mathrm{MEL} \rightarrow \mathrm{IL}\end{array}$ & $\begin{array}{l}\mathrm{BЭY} \rightarrow \Phi O У \\
\mathrm{MEL} \rightarrow \mathrm{FOL}\end{array}$ \\
\hline $\begin{array}{l}\text { ВЭУ - вещественно-энер } \\
\text { social security } \\
\text { ФОУ - функционально-о } \\
\text { organizational level of soci } \\
\text { ИУ - информационный у }\end{array}$ & $\begin{array}{l}\text { хческий урове } \\
\text { низационный } \\
\text { ecurity } \\
\text { ень социально }\end{array}$ & $\begin{array}{l}\text { ииальной безог } \\
\text { нь социальной }\end{array}$ & $\begin{array}{l}\text { и/MEL - Ma } \\
\text { сности/FOL } \\
\text { ation level o }\end{array}$ & $\begin{array}{l}\text { energy level of } \\
\text { ctional- } \\
\text { l security }\end{array}$ \\
\hline
\end{tabular}

Социальная безопасность Атомфлота анализировалась только с 2011 года, т. е. с периода модернизации. До этого предприятие не входило в контур госкорпорации «Росатом»: оно было частью Министерства транспорта страны. Поэтому мы посчитали, что сравнивать социальную безопасность данного атомного предприятия в такие исторические периоды, как становление, расцвет и кризис из-за его вхождения в другую отрасль, некорректно.

Социально-исторический анализ показал, что только социальная безопасность в период расцвета на всех изучаемых атомных предприятиях характеризуется стабильностью, т. е. её уровень остается неизменным на протяжении всего периода. В периоды становления, кризиса и модернизации социальную безопасность не удалось четко определить: она менялась на протяжении периода. Поэтому о ней говорим, используя категорию вероятности, а сами периоды характеризуем как переходные.

Для детального анализа социальной безопасности атомных комбинатов в период модернизации (с 2011 года и по настоящее время) нами изучены представления руководства и работников предприятия. Для понимания позиции руководства проведен контентанализ печатных средств массовой информации. Для этого были использованы как корпоративные газеты («Вестник ГХК», «Вестник Маяка», «Новое время» (СХК), так и городские («Сегодняшняя газета», «Город и горожане», «Диалог», «Вечерний Мурманск», «Мурманский Вестник»). Выбранные для анализа СМИ используются руководством комбинатов для донесения своей позиции по различным вопросам, в том числе и социальным, до работников и жителей городов, где расположены данные атомные предприятия. Представления наёмных работников с помощью массового анкетного опроса удалось изучить только на ГХК. Социологический опрос проходил в 2013 году (выборочная совокупность - 1060 человек) и в 2018-м (выборочная совокупность - 1000 человек), выборка квотная по полу, возрасту, должности и подразделению.

Руководство и работники атомных комбинатов постоянно анализируют социальную среду своих предприятий на наличие рискогенных ситуаций, а также направления социальной политики и заложенные в них меры по минимизации возникающих рисков с 
целью уменьшения их негативных последствий на существующие условия труда. Выявленные в социальной среде риски ранжируются ими через отнесение их к постоянным или эпизодическим. Руководство и работники также оценивают, насколько те или иные меры социальной политики эффективны при минимизации негативных последствий социальных рисков. При этом позиция руководства относительно сложившейся в период модернизации социальной безопасности выглядит оптимистичнее, чем позиция работников. Актуальным для социальной среды ГХК, СХК и Атомфлота руководство считает только один социальный риск - риск падения социальной стабильности предприятия в глазах работника. Остальные риски носят эпизодический характер и не требуют значительного внимания. Для руководства ПО «Маяк» характерно отсутствие в социальной среде комбината постоянного риска, а для уменьшения эпизодических рисков социальная безопасность обладает всеми необходимыми мерами.

Социологический опрос позволил нам изучить представления только работников ГХК. Однако отдельные выводы, которые мы сделали, опираясь на них, могут быть приложены и к другим изучаемым предприятиям. В связи с этим отметим, что значительное влияние на представления работников атомных комбинатов оказывают традиции социальной безопасности, сложившиеся на их предприятии на протяжении всего периода существования, а также рискогенная среда, в которой предприятие находится (моногород, ограниченность рынка труда и т. д.). Работники негативнее, чем руководство, оценивают социальную среду предприятия, больше выявляют социальных рисков и относят их к постоянным, чаще оценивают имеющиеся на предприятии меры отраслевой социальной политики, направленные на минимизацию негативных последствий социальных рисков, как неэффективные. Они также считают, что повысить социальную безопасность предприятия поможет только социальное взаимодействие в форме взаимного диалога между работниками и руководством.

Работники ГХК критичнее руководства оценивают социальную безопасность своего комбината периода модернизации. Они считают, что 6 из 7 возможных рисков на сегодняшний день представлены в его социальной среде. При этом имеющиеся меры социальной политики не могут устранить существующие риски, а сама социальная политика требует корректировки (табл. 3).

Анализ представлений работников и руководства ГХК выявил наличие разногласий в их восприятии социальной безопасности в период модернизации комбината. Причины этого кроются в низком уровне социального взаимодействия, которое сложилось на предприятии. Только верхним иерархическим группам работников (экспертам) доступно общение с руководством, работники нижних иерархических групп редко становятся участниками данной коммуникации. Система каскадирования относительно эффективно работает только сверху вниз, хотя и застревает на уровне руководителей среднего звена (начальников отделов, мастеров). Каскадирование «снизу-вверх» практически не работает. Руководство порой боится идти на открытый диалог с работниками, а работники, хоть и испытывают в этом потребность, не проявляют инициативу для выстраивания взаимного диалога. Это позволяет нам утверждать, что социальное взаимодействие в период модернизации ГХК находится на уровне конкуренции. Результативность социальной безопасности при этом снижается, у работников повышается страх потери вознаграждения за трудовые отношения. В социальной среде предприятия появляются предпосылки для трансформации приемлемого риска в угрозу для дальнейшего существования работника, группы работников или всего предприятия. 


\section{Таблица 3. Сравнительный анализ представлений руководства и работников ГХК о социальной безопасности в период модернизации предприятия}

Table 3. Comparative analysis of the views of the management and employees of the Mining and Chemical Combine about social security during the modernization of the enterprise

\begin{tabular}{|c|c|c|}
\hline $\begin{array}{c}\text { Критерий сравне- } \\
\text { ния } \\
\text { Comparison criterion }\end{array}$ & $\begin{array}{c}\text { Представления руководства } \\
\text { Management views }\end{array}$ & $\begin{array}{c}\text { Представления работников } \\
\text { Employee views }\end{array}$ \\
\hline $\begin{array}{l}\text { Направления соци- } \\
\text { альной политики } \\
\text { Directions of social } \\
\text { policy }\end{array}$ & $\begin{array}{l}\text { Руководство выделяет все } \\
\text { направления социальной поли- } \\
\text { тики, но наибольшее внимание } \\
\text { уделяет только одному. Это } \\
\text { направление, связанное с ощу- } \\
\text { щением работника социальной } \\
\text { стабильности } \\
\text { The leadership identifies all ar- } \\
\text { eas of social policy, but pays } \\
\text { most attention to only one. This } \\
\text { is the direction associated with } \\
\text { the employee's sense of social } \\
\text { stability }\end{array}$ & $\begin{array}{l}\text { Работники выделяют все направления социаль- } \\
\text { ной политики. Уделяют повышенное внимание } 6 \\
\text { на-правлениям из 7. Это направления, связанные } \\
\text { с экономическим благосостоянием работника, } \\
\text { его производственной безопасностью, производ- } \\
\text { ственными условиями труда, ощущением соци- } \\
\text { альной стабильности и получением обратной } \\
\text { связи } \\
\text { Employees identify all areas of social policy. They } \\
\text { pay increased attention to } 6 \text { areas out of } 7 \text {. These are } \\
\text { areas related to the economic well-being of the em- } \\
\text { ployee, his production security, production conditions } \\
\text { of work, a sense of social stability and receiving feed- } \\
\text { back }\end{array}$ \\
\hline $\begin{array}{l}\text { Наличие рисков в } \\
\text { социальной среде } \\
\text { предприятия } \\
\text { Presence of risks in } \\
\text { the social environ- } \\
\text { ment of the enter- } \\
\text { prise. }\end{array}$ & $\begin{array}{l}\text { Характерно преобладание по- } \\
\text { зиции «один постоянный и не- } \\
\text { сколько эпизодических рис- } \\
\text { ков». Постоянный риск - риск } \\
\text { падения социальной стабиль- } \\
\text { ности в глазах работника } \\
\text { Prevalence of the position «one } \\
\text { constant and several episodic } \\
\text { risks» } \\
\text { is characteristic. Constant risk is } \\
\text { the risk of falling social stability } \\
\text { in the eyes of the employee }\end{array}$ & $\begin{array}{l}\text { Характерно преобладание позиции «много по- } \\
\text { стоянных рисков». Всего выделяют } 6 \text { видов } \\
\text { рисков: снижение экономического благососто- } \\
\text { яния, здоровья работника и производственной } \\
\text { безопасности, социально-бытовых условий } \\
\text { труда, падение социальной стабильности и } \\
\text { значимости обратной связи Predominance of } \\
\text { the position «many permanent risks» is } \\
\text { characteristic. In total, } 6 \text { types of risks are distin- } \\
\text { guished: a decrease in economic well-being, em- } \\
\text { ployee health and industrial security, social and } \\
\text { living conditions of work, a drop in social stabil- } \\
\text { ity and the importance of feedback }\end{array}$ \\
\hline $\begin{array}{l}\text { Преобладающий } \\
\text { уровень социаль- } \\
\text { ной безопасности } \\
\text { Prevailing level of } \\
\text { social security }\end{array}$ & $\begin{array}{l}\text { Функционально-организаци- } \\
\text { онный уровень социальной } \\
\text { безопасности. Все потребно- } \\
\text { сти, связанные с вещественно- } \\
\text { энергетическим уровнем, на } \\
\text { предприятии решаются } \\
\text { Functional-organizational level } \\
\text { of social security. All needs re- } \\
\text { lated to the material-energy level } \\
\text { are solved at the enterprise }\end{array}$ & $\begin{array}{l}\text { Вещественно-энергетический уровень соци- } \\
\text { альной безопасности. Социальная политика } \\
\text { предприятия обладает недостаточным набором } \\
\text { мер даже для того, чтобы защитить существу- } \\
\text { ющие условия труда, удовлетворяющие повсе- } \\
\text { дневные потребности работника } \\
\text { Material-energy level of social security. The so- } \\
\text { cial policy of the enterprise has an insufficient set } \\
\text { of measures even to protect the existing working } \\
\text { conditions that satisfy the daily needs of the em- } \\
\text { ployee }\end{array}$ \\
\hline
\end{tabular}

\section{Вывод}

Итак, созданная нами теоретическая модель социальной безопасности применима к изучению социальной безопасности конкретного российского предприятия. Использование эмпирических данных подтвердило это. Тем самым цель статьи представляется достигнутой. В завершении отметим, что анализ представлений руководства и работников отдельных промышленных предприятий атомной отрасли показал необходимость 
диалога между субъектами управленческой вертикали предприятия. Повышения социальной безопасности можно добиться только при работе в связке «работник-руководитель» и при переходе социального взаимодействия от конкуренции к кооперации. При этом важную роль должны играть система обратной связи и мониторинговые исследования представлений персонала предприятия о социальной безопасности.

\section{СПИСОК ЛИТЕРАТУРЫ}

1. Дуглас М. Риск как судебный механизм // THESIS. - 1994. - № 5. - Вып. 5. - С. 242-253. URL: http://riskprom.ru/publ/38-1-0-217 (дата обращения 09.09.2020).

2. Бек У. Общество риска. На пути к другому модерну. - М.: Прогресс-Традиция, 2000. - 146 с.

3. Луман Н. Общество как социальная система. - М.: Логос, 2004. -232 с.

4. Гидденс Э. Ускользающий мир: как глобализация меняет нашу жизнь. - М.: Весь Мир, 2004. -120 с.

5. Альгин А.П. Риск и его роль в общественной жизни. - М.: Мысль, 1989. -188 с.

6. Гринберг М.С. Преступное невежество как форма преступной неосторожности // Вестник Омского университета. - 2009. - № 3. - С. 224-229.

7. Зубков В.И. Проблемное поле социологической теории риска // СоцИс. - 2001. - № 6. - С. 122-127.

8. Никитин С.М., Феофанов К.А. Социологическая теория риска в поисках предмета // СоцИс. - 1992. № 10. - C. $120-127$.

9. Феофанов К.А. Российская социология риска: состояние и перспективы // СоцИс. - 2007. - № 4. - С. 3 12.

10. Веблен Т. Теория праздного класса. - М.: Прогресс, 1984. - 197 с.

11. Коммонс Дж. Правовые основания капитализма. - М.: ГУ-ВШЭ, 2011. - 416 с.

12. Сухарев О.С. Новая программа исследований в экономике: традиция «старого» институционализма и современность // Журнал экономической теории. - 2013. - № 4. - С. 23-36.

13. Гамильтон У.Х. Институциональный подход к экономической теории // Экономический вестник Ростовского государственного университета. - 2007. - Т. 5. - № 2. - С. 110-117.

14. Иншаков О.В. Экономические институты и институции: к вопросу о типологии и классификации // Социологические исследования. - 2003. - № 9. - С. 42-51.

15. Осипов Г.В. Прелюдия XXI века // Социологические исследования. - 2014. - № 6. - С. 44-52.

16. Радаев В.В., Шкаратан О.И. Социальная стратификация. - М.: Аспект Пресс, 1995. - 318 с.

17. Заславская Т.И. Социоструктурный аспект трансформации российского общества // СоцИс. - 2001. № 8. - С. 8-11.

18. Калугина 3.И. Социальные риски модернизации российской аграрной экономики // Отечественные записки. - 2012. - № 6 (51). - С 117-129.

19. Гидденс Э. Устроение общества: очерк теории структурации. - М.: Академический проект, 2018. - 528 c.

20. Кирдина С.Г. Институциональные матрицы и развитие России: введение в X-Y теорию. - СПб.: Нестор-История, 2014. - 468 с.

21. Кареева А.П. Социологический анализ представлений работников Горно-химического комбината о социальной безопасности предприятия в период модернизации // SIBERIAN SOCIUM. - 2018. - T. 2. № 2. - C. 53-67.

22. Тощенко Ж.Т., Цветкова Г.А. Социология труда. - М.: Центр социального прогнозирования и маркетинга, 2012. - 407 c.

23. Ильиных С.А. Социология управления: роль зарубежных школ в становлении // Идеи и идеалы. -2015 . - T. 1. - № 2 (24). - C. 94-105.

24. Добрина О.А. Представления о человеке труда в классической социологии управления организацией: Фредерик Тейлор и Элтон Мэйо // Вестник Пермского университета. - 2019. - № 4. - С. 412-420.

25. Гастев А.К. Как надо работать. Практическое введение в науку организации труда. - М.: Экономика, 196. $-478 \mathrm{c}$.

26. Здравомыслов А., Ядов В. Человек и его работа в СССР и после: учебное пособие для вузов. - М.: Аспект Пресс, 2003. - 485 с.

27. Шкаратан О.И. Государственная социальная политика и положение средних слоев в современной России // Социологический журнал. - 2004. - № 1-2. - С. 106-128.

28. Фролов С.С. Ролевая неопределенность как фактор и условие эффективного управления социальными процессами в современных организациях // Вестник Университета (Государственный университет управления). - 2017. - № 11. - С. 173-179. 
29. Немировский В.Г. Универсумный подход к динамике социальных систем: анализ и прогнозирование. - Красноярск: Красноярский государственный университет, 2003. - 173 с.

Поступила 12.12.2020 2. 
UDC 330.7:334.012.62(47+57)

\title{
SOCIOLOGICAL ANALYSIS OF SOCIAL SECURITY OF A MODERN LARGE RUSSIAN ENTERPRISE
}

\author{
Anna P. Kareeva, \\ karenina3010@rambler.ru
}

\begin{abstract}
Northern (Arctic) Federal University named after M.V. Lomonosov, 17, Severnaya Dvina embankment, Arkhangelsk, 163002, Russia
\end{abstract}

\begin{abstract}
Anna P. Kareeva, applicant, Northern (Arctic) Federal University named after M.V. Lomonosov.
\end{abstract}
The relevance of the study is determined by the presence in modern society of a significant number of risks and the desire of people living in it to protect themselves from their negative impact. Social life in such a risky society is characterized by uncertainty. Institutional risk environments encompass both individual social groups and all of humanity. At the same time, security acts as a restraining element that does not allow destroying the existing social structure of a given society, and social security is capable of mitigating the social risks arising in it. Purpose of the work is to study the social security of a modern large Russian enterprise, create a theoretical model and carry out its practical analysis. Methods. The works of scientists who formed the main approaches to understanding the concept of «risk society», the theory of institutional matrices, social security, sociology of labor and the universal sociological paradigm became the theoretical and methodological base of the research. As part of the study, a socio-historical analysis of open documentary sources, a content analysis of print media, a questionnaire survey and a comparative analysis of the views of the management and employees of individual industrial enterprises of the nuclear industry were carried out. Results. The main characteristics of social risk are revealed and its definition is given, the social sphere of a modern risk-generating society is described. At the same time, security is considered as the basic social institution of such a society. It highlights the «internal structure» of the institution and its institutional forms. One of these forms defines social security. The analysis of the social security of a large Russian enterprise was carried out at various levels of society (macro-, meso- and microlevels), and a theoretical model was created. A practical analysis of the theoretical model of social security was carried out at individual industrial enterprises of the nuclear industry. Such enterprises are MCC (Zheleznogorsk, Krasnoyarsk Territory), SHK (Seversk, Tomsk Region), PA Mayak (Ozersk, Chelyabinsk Region) and Atomflot (Murmansk, Murmansk Region).

Key words: Security, social security, institution, risky society, social risk, industrial enterprise.

\section{REFERENCES}

1. Douglas M. Risk kak sudebny mekhanizm [Risk as a judicial mechanism]. THESIS, 1994, no. 5, pp. $242-253$. Available at: http://riskprom.ru/publ/38-1-0-217 (accessed 9 September 2020).

2. Beck U. Obshchestvo riska. Na puti k drugomu modernu [Risk society. On the way to another modern]. Moscow, Progress-Tradition Publ., 2000. 146 p.

3. Luhmann N. Obshchestvo kak sotsialnaya sistema [Society as a social system]. Moscow, Logos Publ., 2004. $232 \mathrm{p}$.

4. Giddens E. Uskolzayushhiy mir: kak globalizatsiya menyaet nashu zhizn [The whispered world: how globalization is reshaping our lives]. Moscow, Ves mir Publ., 2004. 120 p.

5. Algin A.P. Risk i ego rol v obshchestvennoy zhizni [Risk and its role in public life]. Moscow, Mysl Publ., 1989. $188 \mathrm{p}$.

6. Grinberg M.S. Prestupnoe nevezhestvo kak forma prestupnoy neostorozhnosti [Criminal ignorance as a form of criminal negligence]. Vestnik Omskogo universiteta, 2009, no. 3, pp. 224-229.

7. Zubkov V.I. Problemnoe pole sotsiologicheskoy teorii riska [The problem field of the sociological theory of risk]. Sotsiologicheskie issledovaniya, 2001, no. 6, pp. 122-127. 
8. Nikitin S.M., Feofanov K.A. Sotsiologicheskaya teoriya riska v poiskakh predmeta [Sociological theory of risk in search of a subject]. Sotsiologicheskie issledovaniya, 1992, no. 10, pp. 120-127.

9. Feofanov K.A. Rossiyskaya sotsiologiya riska: sostoyanie i perspektivy [The Russian sociology of risk: status and prospects]. Sotsiologicheskie issledovaniya, 2007, no. 4, pp. 3-12.

10. Veblen T. Teoriya prazdnogo klassa [Theory of the leisure class]. Moscow, Progress Publ., 1984. 197 p.

11. Commons J. Pravovye osnovaniya kapitalizma [Legal foundations of capitalism]. Moscow, GU-VhSE Publ., $2011.416 \mathrm{p}$.

12. Sukharev O.S. Novaya programma issledovaniy v ekonomike: traditsiya «starogo» institutsionalizma i sovremennost [New research program in Economics: the tradition of «old» institutionalism and modernity]. Zhurnal ekonomicheskoy teorii, 2013, no. 4, pp. 23-36.

13. Hamilton W.H. Institutsionalny podkhod k ekonomicheskoy teorii [Institutional approach to economic theory]. Ekonomicheskiy vestnik Rostovskogo gosudarstvennogo universiteta, 2007, vol. 5, no. 2, pp. 110-117.

14. Inshakov O.V. Ekonomicheskie instituty i institutsii: k voprosu o tipologii i klassifikatsii [Economic institutions and institutions: on the question of typology and classification]. Sotsiologicheskie issledovaniya, 2003, no. 9, pp. 42-51.

15. Osipov G.V. Prelyudiya XXI veka [Prelude of the XXI century]. Sotsiologicheskie issledovaniya, 2014, no. 6, pp. $44-52$.

16. Radaev V.V., Shkaratan O.I. Sotsialnaya stratifikatsiya [Social stratification]. Moscow, Aspect Press Publ., 1995. $318 \mathrm{p}$.

17. Zaslavskaya T.I. Sotsiostrukturny aspekt transformatsii rossiyskogo obshhestva [Socio-structural aspect of transformation of Russian society]. Sotsiologicheskie issledovaniya, 2001, no. 8, pp. 8-11.

18. Kalugina Z.I. Sotsialnye riski modernizatsii rossiyskoy agrarnoy ekonomiki [Social risks of modernization of the Russian agricultural economy]. Otechestvennye zapiski, 2012, no. 6 (51), pp. 117-129.

19. Giddens E. Ustroenie obshhestva: ocherk teorii strukturatsii [The organization of society: an essay on the theory of structuration]. Moscow, Academic project Publ., 2018. 528 p.

20. Kirdina S.G. Institutsionalnye matritsy i razvitie Rossii: vvedenie $v X-Y$ teoriyu [Institutional matrices and the development of Russia: an introduction to X-Y theory]. St. Petersburg, Nestor History Publ., 2014. 468 p.

21. Kareeva A.P. Sotsiologicheskiy analiz predstavleniy rabotnikov Gorno-khimicheskogo kombinata o sotsialnoy bezopasnosti predpriyatiya v period modernizatsii [Sociological Analysis of the Representations of Large Industrial Enterprise in Siberia on Social Security in the Period Modernization]. SIBERIAN SOCIUM, 2018, vol. 2, no. 2, pp. 53-67.

22. Toshchenko Zh.T., Tsvetkova G.A. Sotsiologiya truda [Sociology of work]. Moscow, Tsentr sotsialnogo prognozirovaniya i marketinga Publ., 2012. 407 p.

23. Ilinykh S.A. Sotsiologiysa upravleniya: rol zarubezhnykh shkol v stanovlenii [Sociology of management: the role of foreign schools in the formation]. Idei i idealy, 2015, vol. 1, no. 2 (24), pp. 94-105.

24. Dobrina O.A. Predstavleniya o cheloveke truda v klassicheskoy sotsiologii upravleniya organizatsiey: Frederik Teylor i Jelton Myeyo [Representations of the labor man in the classical sociology of organization management: Frederick Taylor and Elton Mayo]. Vestnik Permskogo universiteta, 2019, no. 4, pp. 412-420.

25. Gastev A.K. Kak nado rabotat. Prakticheskoe vvedenie v nauku organizatsii truda [How to work. Practical introduction to the science of labor organization]. Moscow, Economika Publ., 1972. 478 p.

26. Zdravomyslov A., Yadov V. Chelovek i ego rabota v SSSR i posle [Man and his work in the USSR and after]. Moscow, Aspect-Press Publ., 2003. 485 p.

27. Shkaratan O.I. Gosudarstvennaya sotsialnaya politika i polozhenie srednikh sloev v sovremennoy Rossii [State social policy and the situation of the middle classes in modern Russia]. Sotsiologicheskiy zhurnal, 2004, no. $1-2$, pp. 106-128.

28. Frolov S.S. Rolevaya neopredelennost kak faktor i uslovie effektivnogo upravleniya sotsialnymi protsessami $\mathrm{v}$ sovremennykh organizatsiyakh [Role uncertainty as a factor and condition for effective management of social processes in modern organizations]. Vestnik Universiteta (Gosudarstvenny universitet upravleniya), 2017, no. 11 , pp. 173-179.

29. Nemirovsky V.G., Kudryavtseva V.I. Universumny podkhod k dinamike sotsialnykh sistem: analiz i prognozirovanie [Universal approach to the dynamics of social systems: analysis and forecasting]. Krasnoyarsk, Krasnoyarskiy gosudarstvenny universitet Publ., 2003. 173 p.

Received: 12 December 2020. 